\title{
O Pacto Nacional pelo Fortalecimento do Ensino Médio e a Formação de Professores no Ceará
}

\author{
Maria Cibelle Moreira de Araújo \\ Universidade Estadual do Ceará - UECE \\ Profa. Dra Isaurora Cláudia Martins de Freitas \\ Universidade Estadual do Ceará - UECE
}

\begin{abstract}
Resumo
0 artigo apresenta alguns resultados de uma pesquisa que investigou a implementação do Pacto Nacional pelo Fortalecimento do Ensino Médio - PNEM, na Coordenadoria Regional de Desenvolvimento da Educação- CREDE 06 - Sobral, a fim de entender como se efetivou a formação de professores, ação estruturante do Pacto, e o que ela trouxe para os que dela participaram. Duas escolas pertencentes à CREDE 06 - Sobral foram referências para o levantamento de dados da pesquisa que adotou uma abordagem qualitativa, cujo principais instrumentos foram a análise documentação e as entrevistas semiestruturadas com professores e com técnicos que atuaram na implementação do Pacto. 0 embasamento teórico partiu de autores que contribuíram para discutir categorias como política pública, política educacional, e formação de professores. 0 estudo apontou que, para alguns, o Pacto gerou movimentos e conseguiu provocar um diálogo entre os diversos atores envolvidos na sua implementação, cuja formação de professores, realizada no "chão da escola", possibilitou a troca de experiências e de reflexões sobre o fazer pedagógico. Para outros, as formações não trouxeram nada de positivo, além da bolsa que era paga aos participantes.
\end{abstract}

Palavra-chave políticas educacionais; ensino médio; formação de professores; PNEM

\begin{abstract}
The article presents some results of a research that investigated the implementation of the National Pact for the Strengthening of Secondary Education - PNEM, in the Regional Coordination for the Development of Education - CREDE 06 - Sobral, in order to understand how teacher training was carried out, a structuring action of the Pact, and what it brought to those who participated in it. Two schools belonging to CREDE 06 - Sobral were references for collecting research data that adopted a qualitative approach, whose main instruments were the documentation analysis and semi-structured interviews with teachers and technicians who worked on the implementation of the Pact. The theoretical basis came from authors who contributed to discuss categories such as public policy, educational policy, and teacher training. The study pointed out that, for some, the Pact generated movements and managed to provoke a dialogue between the various actors involved in its implementation,
\end{abstract}


whose teacher training, carried out on the "school floor", made it possible to exchange experiences and reflections on doing pedagogical. For others, the training did not bring anything positive, besides the scholarship that was paid to the participants.

Key-word educational policies; high school; teacher training; PNEM

\section{Introdução}

O ensino médio se destaca como o grande desafio da educação brasileira da atualidade, sendo um campo que recebe cada vez mais investimentos, embora ainda distantes das necessidades. Mudar o ensino médio é uma necessidade na medida em que o contexto social brasileiro evidencia:

\footnotetext{
- Novas exigências educacionais resultantes das transformações na produção de conhecimento e no acesso às informações, no mundo do trabalho e nos próprios interesses dos jovens estudantes;

- Diversidade desses jovens, o que implica "reconhecer diferentes caminhos de atendimento aos variados anseios das 'juventudes' e da sociedade" (BRASIL, 2012, p. 4).
}

Até a década de 1990 o ensino médio não era obrigatório no Brasil. Com o advento da Lei 6.364/96, tornou-se um direito social, mas somente em 2010 teve a sua universalidade e gratuidade asseguradas por lei1. A partir dos anos 2000, portanto, o que se tem é um processo, que ainda é vivenciado, de expansão na oferta desta etapa de ensino, o que implica mudanças, que ainda não se concluíram (TARTUCE, et al, 2018), visando à democratização e a garantia da qualidade.

De acordo com dados do Censo da Educação Básica do Inep/MEC de 2018, divulgados em 2019, o Brasil possui 7.709.929 matriculados no ensino médio, uma redução de 220.455 matrículas se comparado ao ano de 2017, seguindo, portanto, a tendência de queda verificada nos últimos cinco anos. No que se refere à evasão, o índice foi de 6,1\%, totalizando 433.052 alunos que deixaram de frequentar as escolas de ensino médio². Estes índices envolvem vários aspectos e se mostram, na atualidade, como o grande desafio a ser enfrentado além das questões de ensino e aprendizado.

Os números do Índice de Desenvolvimento da Educação Básica (IDEB) mostram que há cinco anos o ensino médio vem ficando abaixo das metas do governo. Em 2013, a meta era de 3,6, tendo sido alcançado uma média 3,4, em 2015 a meta era 4,0, tendo sido alcançado meta 3,5, já em 2017 a meta era 4,4 e tenha permanecido a média de 3,5, situações que levam todos os que se inserem no sistema de ensino a pensar ações para a melhoria do ensino médio (INEP/MEC, 2018).

1 A Lei Ordinária n. 12.061 de 27 de outubro de 2009, fruto do Projeto de Lei n. 7.409/06, de autoria do senador Cristovam Buarque, estabeleceu a universalização do ensino médio gratuito e passou a vigorar no dia 1을 de janeiro de 2010.

2 Ver mais em:

http://download.inep.gov.br/educacao_basica/censo_escolar/notas_estatisticas/2018/notas_estatisticas_cens o_escolar_2018.pdf 
O Pacto Nacional pelo Fortalecimento do Ensino Médio (PNEM) foi criado pelo Ministério da Educação (MEC), em 2013, como uma das ações voltadas para superar referidos índices que apontam as fragilidades desse nível de ensino. Nesse sentido, ele foi pensado como parte das políticas públicas de educação do Governo Dilma Roussef (20122016), integrando ações já iniciadas no governo anterior com o propósito de cumprir o que preveem as Diretrizes Curriculares Nacionais para o Ensino Médio (Resolução CEB/CNE, n. 2 de 30 de janeiro de 2012), que elegem o trabalho, a cultura, a ciência e a tecnologia como dimensões que deverão integrar os conhecimentos de todas as áreas que compõem o currículo do Ensino Médio (BRASIL, 2012).

Segundo Secchi (2010), qualquer definição de política pública é arbitrária, pois não há consenso na literatura especializada sobre questionamentos básicos. Neste estudo, achamos pertinente adotar a definição de Adams (2006), por considerá-la mais abrangente. Segundo o autor, políticas públicas

\begin{abstract}
“São ações públicas assumidas pelos governos, instituições públicas estatais, com ou sem participação da sociedade, que concretizam direitos humanos coletivos ou direitos sociais garantidos em lei. Não se pode falar em política pública fora da relação estado e sociedade. Ela compreende tudo o que o Estado faz ou deixa de fazer: o investimento, os segmentos beneficiados ou excluídos pelos serviços." (ADAMS, 2006, p. 1)
\end{abstract}

Se política pública "é tudo o que o Estado faz ou deixa de fazer", política educacional é tudo aquilo que um Estado faz ou deixa de fazer em educação, ou seja, "a política educacional diz respeito às decisões que o Poder Público, isto é, o Estado, toma em relação à educação." (SAVIANI, 2008, p.7). Ampliando o conceito, Martins (1994) afirma que

\begin{abstract}
A política educacional é um dos instrumentos para se projetar a formação dos tipos de pessoas de que uma sociedade necessita. (...) definindo a forma e o conteúdo do saber que vai ser passado de pessoa a pessoa para constituir e legitimar seu mundo, e visando, com isso, assegurar a sobrevivência dos diversos tipos de sociedade. (MARTINS, 1994, p. 9).
\end{abstract}

Neste artigo, analisamos a formação de professores ofertada pelo Pacto Nacional pelo Fortalecimento do Ensino Médio (PNEM) no Ceará, como um dos componentes da recente política educacional brasileira. 0 intuito foi compreender como se deu seu processo de implantação e desenvolvimento e que contribuições trouxe para duas escolas de ensino médio da 6 ${ }^{\text {a }}$ Coordenadoria Regional de Desenvolvimento da Educação (CREDE), sediada em Sobral, após a concretização das etapas iniciais do Programa ${ }^{3}$. As escolas escolhidas como campo de pesquisa foram a Escola de Ensino Médio Jarbas Passarinho, localizada na sede do Município de Sobral e a Escola de Ensino Médio José Cláudio de Araújo, situada no Centro do município de Mucambo. 0 critério de escolha das escolas foi o grau de dificuldade ou facilidade no processo de implementação do Pacto, portanto, uma teve dificuldade e a outra teve facilidade.

3 A pesquisa que serviu de base para as análises aqui contidas foi realizada para a dissertação de mestrado da primeira autora (ARAÚJO, 2019). 
A temática aqui apresentada possui relevância por estar inserida no contexto político e socioeconômico em que tem havido uma série de modificações no ensino médio brasileiro, que se justificam pelos índices das avaliações externas como a Avaliação Nacional da Educação Básica- ANEB, utilizada para calcular IDEB, e o Exame Nacional do Ensino Médio- ENEM, além de dados que retratam uma modalidade de ensino com alto índice de evasão escolar e um número elevado de jovens fora deste nível de escolaridade. Portanto, buscamos contribuir com a produção bibliográfica nacional já existente, como os estudos contidos em Vasconcelos (2017) e o de Freitas e Cruz (2015), ampliando os estudos sobre a aprendizagem cooperativa como aparato para a formação continuada de professores a partir da realidade específica de escolas do interior do Ceará.

A escolha da temática deveu-se ao fato da primeira autora deste artigo ser professora do Ensino Médio e ter atuado no Pacto como orientadora de formação, no município de Uruoca, situado também na 6a . CREDE. Tal atuação fez surgir o desejo de saber como se deu a implantação das formações em outras escolas da mesma regional. Quais as possibilidades e limitações apresentadas por este programa nas escolas pesquisadas? Quais as possíveis contribuições das formações de professores ofertadas pelo PNEM na Crede 06? Que dificuldades nas formações foram apontadas pelos professores das escolas pesquisadas?

A fim de responder tais questões, foi realizada, entre os anos 2018 e 2019, uma pesquisa que combinou técnicas quantitativas e técnicas qualitativas.

Segundo Tim May (2004), métodos podem ser complementares, nesse sentido tornou-se comum pesquisadores qualitativos usarem também o método quantitativo, de forma complementar. Nesse sentido, integrar pesquisa quantitativa e qualitativa "permite que o pesquisador faça um cruzamento de suas conclusões de modo a ter maior confiança que seus dados não são produto de um procedimento específico ou de alguma situação particular". (GOLDENBERG, p.36, 1997)

Assim, além da pesquisa bibliográfica em livros, artigos, dissertações e teses que permitiram construir um arcabouço teórico destinado a discutir política pública, política educacional, ensino médio e formação de professores, foi realizada uma pesquisa documental em leis, decretos e documentos oficiais para entender o ciclo do PNEM como política pública e ainda uma pesquisa empírica com a aplicação de questionários, destinados a coletar informações e opiniões dos professores que participaram das formações oferecidas pelo Pacto, e ainda a realização de entrevistas semiestruturadas com técnicos que participaram do processo de implementação da referida política no Ceará.

Os resultados da pesquisa serão apresentados em duas partes, na primeira, apresentaremos a formação de professores no Pacto Nacional pelo Fortalecimento do Ensino Médio e sua implantação no Ceará. A seguir, mostraremos como ele foi executado na EEM Ministro Jarbas Passarinho e na EEM José Cláudio de Araújo e que contribuições e dificuldades foram percebidas nas referidas escolas.

\section{A Formação de Professores no PNEM}

Em 2013, quando Aloízio Mercadante era ministro da educação, em consonância com as Novas Diretrizes Curriculares para o Ensino Médio (DCNEM), de 31 de janeiro de 2012, entra em vigor no Brasil o Pacto Nacional pelo Fortalecimento do Ensino Médio (PNEM). O Programa é regulamentado pela Portaria Ministerial № 1.140, de 22 de novembro de 2013. Através dele, o Ministério da Educação e as secretarias estaduais e distrital de educação assumiram o compromisso de elaborar e implantar ações voltadas à 
elevação da qualidade do ensino médio brasileiro e à inclusão de todos os que a ele tenham direito ${ }^{4}$. A articulação para a adesão e conhecimento das propostas do Pacto iniciou em 31 de outubro de 2013 por meio do seminário de lançamento.

O marco legal que fundamenta o Pacto está permeado por lutas e reformas realizadas ao longo de quase 30 anos e pelas mudanças ocorridas na década de 1990. A Constituição de 1988, em seu artigo 208, abriu caminhos e fortaleceu o papel do ensino médio, trazendo a concepção de que este nível de ensino é dever do Estado e garantindo a sua oferta e gratuidade. Já a Lei de Diretrizes e Bases da Educação Nacional (LDBN- lei no 9394/96) determina, em seu artigo 22, que o ensino médio "tem por finalidade desenvolver o educando, assegurar-lhe a formação comum indispensável para o exercício da cidadania e fornecer-lhe maios para progredir no mundo do trabalho e em estudos posteriores". 0 Plano Nacional de Educação prevê, em seu artigo II, "a superação das desigualdades educacionais, com ênfase na promoção da cidadania e na erradicação de todas as formas de discriminação, a melhoria da qualidade da educação, e a valorização dos profissionais de educação".

Com base nos referidos documento, o Pacto elegeu, em sua fase inicial, duas ações estratégicas: o redesenho dos currículos das escolas, através do Programa Ensino Médio Inovador (Pro-EMI) 5 , e a formação continuada de professores e coordenadores pedagógicos que atuam no ensino médio público, nas áreas rurais e urbanas. Nossa análise deteve-se apenas na segunda estratégia, cuja execução foi iniciada no primeiro semestre de 2014, através da parceria entre secretárias estaduais de educação e universidades, pois uma das metas a ser alcançada era a aproximação entre a educação básica e a superior para que, no desenvolver do processo, essas duas etapas escolas e universidades rediscutissem a formação do professor em caráter inicial e contínuo. (BRASIL, 2012).

A participação dos professores foi realizada mediante adesão dos interessados e cadastro, realizado pelo diretor da escola onde o interessado leciona. Cada professor participante teve direito a uma bolsa de $\mathrm{R} \$ 200,00$, valor irrisório, se considerarmos a sobrecarga de trabalho dos docentes das escolas públicas. Os encontros formativos foram realizados "no chão da escola" e assumiram um caráter de formação colaborativa, realizada entre seus pares, objetivando melhorar a qualidade do ensino médio; ampliar os espaços de formação dos profissionais envolvidos nesta etapa da educação; promover a reflexão sobre as práticas curriculares desenvolvidas nas escolas; fomentar o desenvolvimento de práticas educativas focadas na formação humana integral, conforme as DCNEM. ${ }^{6}$

No Estado do Ceará, de acordo com Vasconcelos (2017), o Pacto envolveu em ações de formação 16.6547 professores, nos 184 municípios do Estado, distribuídos em 621 escolas da rede estadual, que oferecem o ensino médio, por meio de um diálogo interinstitucional entre a secretaria de educação, organizada a partir de 21 Coordenadorias Regionais de Desenvolvimento da Educação (CREDE e SEFOR), as instituições de ensino superior e as escolas.

A Universidade Federal do Ceará (UFC) foi responsável pela coordenação geral. As demais universidades parceiras, responsáveis pela coordenação adjunta do Pacto, foram:

4 Ver em: http://pactoensinomedio.mec.gov.br/index.php?option=com content\&view=article\&id=1:pactopelo-fortalecimento-do-ensino-medio\&catid=8\&Itemid=101

5 Ver em: http://portal.mec.gov.br/index.php?option=com content\&view=article\&id=13439\&Itemid=1038

6 Informações encontradas em:

http://pactoensinomedio.mec.gov.br/index.php?option=com_content\&view=article\&id=22

7 Há época, o Ceará possuía 16.984 professores atuando no Ensino Médio. 
Universidade Estadual do Ceará (UECE), Instituto Federal do Ceará (IFCE), Universidade Estadual Vale do Acaraú (UVA), Universidade Federal do Cariri (UFCA) e Universidade da Integração Internacional da Lusofonia Afro-Brasileira (UNILAB).

O lançamento do Pacto no Estado do Ceará ocorreu no dia 28 de março de 2014, sendo realizado o evento na Escola de Educação Profissional (EEEP) Jaime Alencar, em Fortaleza, e contou com a participação dos agentes responsáveis pela implantação em nosso Estado: instituições de Ensino Superior (IS), supervisores da Secretaria de Educação (SEDUC), professores formadores regionais, representantes do conselho de educação do Estado e sindicato de professores.

A coordenação do Pacto no Estado coube à UFC e a supervisão, na secretaria de educação, foi feita por 05 supervisores. As formações foram realizadas por 45 formadores regionais, que, por sua vez, replicaram as formações para um universo de 1.187 orientadores de estudo, que atuaram como multiplicadores, orientando o processo de formação presencialmente nas escolas para os outros professores. Cabe destacar que o processo de seleção dos formadores regionais se deu por meio de edital e processo seletivo (entrevista e prova de título) organizado pela SEDUC, já os orientadores de estudo foram aclamados por seus pares em processos de escolhas realizadas nas unidades escolares de origem.

Em linhas gerais, os trabalhos em prol de mudanças no ensino médio no Ceará iniciaram com o Pacto, em 2014, quando da consulta e formação de professores multiplicadores. A formação visava mudar as metodologias e abordagens no ensino médio a partir da escuta, formação e multiplicação com professores e gestores escolares, o que significa mudanças conceituais e metodológicas em sala de aula. Um dos primeiros desafios, nesse contexto, foi formar, nos professores, percepções sobre multidisciplinaridade, interdisciplinaridade e transdisciplinaridade.

A multidisciplinaridade é o que já se pratica nas escolas, onde as diferentes disciplinas são ministradas de forma independente por cada professor. A interdisciplinaridade vai além da multidisciplinaridade, pois é compreendida como a interação entre disciplinas que mantêm suas identidades, mas dialogam entre si em busca de um objetivo comum. A perspectiva transdisciplinar, defendida por Edgar Morin (1991), parte da ideia de que não deve haver segmentação do conhecimento através de disciplinas, pois o conhecimento é algo muito complexo e nenhum saber é mais importante que o outro, assim, deve-se adotar uma perspectiva holística onde o diálogo horizontal entre as diversas formas de conhecimento fará com que os saberes se interpenetrem formando um todo indissociável.

A multidisciplinaridade já é praticada pelos educadores, a interdisciplinaridade é conhecida, mas pouco praticada, e a transdisciplinaridade é, para muitos, desconhecida e de difícil compreensão.

As formações buscaram ainda um processo de discussão sobre a construção de um ensino médio inovador, levando o professor a refletir sobre os jovens como sujeitos do ensino médio, a fim de enfrentar visões enraizadas sobre este público, construindo novos diálogos com a juventude, pois, para compreender tal categoria se faz necessário conhecêla, levando em conta a heterogeneidade nos modos de ser jovem e a condição juvenil (DAYRELL, 2007).

De acordo com Mascarenhas (2011), "a formação é de grande importância ao trabalho docente, pois, a partir desta, o docente construirá seu saber pedagógico" (MASCARENHAS, 2011, p. 224). No entanto, o que entendemos por formação vai além 
daquilo que se aprende nos cursos e capacitações. Assim como o artesão, o professor aprende com seus mestres de ofício, mas também vai criando suas próprias técnicas a partir dos conteúdos programáticos e dos saberes acumulados pela experiência e pelo contato com a realidade (SILVA, 2009, p.68) e neste processo, a formação contínua é de fundamental importância, ainda mais se possibilita a troca com os pares e a reflexão crítica sobre a própria prática.

Do ponto de vista teórico, as formações propostas pelo PNEM apostaram nessa perspectiva. No entanto, o Programa teve vida curta, pois foi encerrado em 2015, em meio à grave crise política e econômica que culminou com o impeachement da presidente Dilma Roussef, em 2016. Vejamos a seguir o que ficou dessas formações nas escolas pesquisas.

\section{As formações do PNEM nas escolas Jarbas Passarinho e José Cláudio de Araújo}

As formações do PNEM partiram do reconhecimento da escola como espaço de "ação-reflexão-ação" e como unidade básica de mudança, desenvolvimento e melhoria da qualidade do ensino. Assim, transformaram a escola "em lugar de formação prioritária diante de outras ações formativas". (IMBERNÓN, 2001, p. 84).

Apresentamos aqui uma síntese dos dados coletados através da pesquisa de campo realizada na Crede 06 - Sobral, nas escolas de ensino médio Ministro Jarbas Passarinho, em Sobral e José Claúdio de Araújo, em Mucambo. A intenção foi refletir sobre as formações de professores ofertadas pelo Pacto na Crede 06 a partir da visão dos que delas participaram.

A primeira escola possuía, na época da pesquisa, 703 alunos, distribuídos nos turnos manhã, tarde e noite, com 18 turmas em funcionamento e 41 professores, dos quais 36 participaram das formações ofertadas pelo Pacto. A escola de Mucambo possuía 468 alunos, distribuídos em 14 turmas de ensino médio, nos três turnos e um total de 30 professores, dois quais 26 participaram das formações.

As formações de professores aconteceram nos planejamentos por área de conhecimento, que equivale a $1 / 3$ da regência em sala, fato que gerou algumas críticas, pois este momento deve ser utilizado para o planejamento das aulas, preparação de atividades dentre outros.

As duas escolas pesquisadas, embora situadas na mesma regional, ofertando o mesmo nível de ensino, trazem realidades diferentes e olhares diferenciados sobre o Pacto. A partir da análise feita, observamos que as propostas do Pacto foram mais bem aceitas na EEM José Cláudio do que na EEM Ministro Jarbas Passarinho, como poderemos ver no quadro a seguir, que traz algumas falas dos professores analisando as contribuições e as dificuldades verificadas nas formações ofertadas pelo Pacto.

\section{Quadro 1 - Contribuições e dificuldades das formações continuadas na visão dos professores}

\begin{tabular}{|l|l|}
\hline \multicolumn{1}{|c|}{ Contribuições } & \multicolumn{1}{c|}{ Dificuldades } \\
\hline Formação continuada, atualização sobre as & O tempo reduzido para a aplicação das atividades \\
políticas educacionais e trocas de conhecimento & $\begin{array}{l}\text { previstas; falta de continuidade do projeto e falta } \\
\text { entre o corpo docente e o professor orientador de } \\
\text { estudo. (Profa. Bia, EEM Min. Jarbas }\end{array}$ \\
$\begin{array}{l}\text { Passarinho). } \\
\text { (Profa. Bia). }\end{array}$
\end{tabular}




\begin{tabular}{|l|l|}
\hline $\begin{array}{l}\text { A única coisa boa que eu vi sendo ofertada foi a } \\
\text { bolsa de 200,00 reais. (Profa. Paula, EEM Min. } \\
\text { Jarbas Passarinho). }\end{array}$ & $\begin{array}{l}\text { Não houve continuação, o projeto terminou antes } \\
\text { do período previsto. (Profa. Paula). }\end{array}$ \\
\hline $\begin{array}{l}\text { Nenhuma. (Prof. Beto- EEM Min. Jarbas } \\
\text { Passarinho). }\end{array}$ & $\begin{array}{l}\text { Não eram transmitidos de forma clara os trabalhos } \\
\text { (debates) que deveriam ser realizados pelos } \\
\text { professores orientadores de estudo, o que, às } \\
\text { vezes, desmotivava os professores na } \\
\text { participação. (Prof. Beto). }\end{array}$ \\
\hline $\begin{array}{l}\text { Mais conhecimento para os professores usarem } \\
\text { em sala para facilitar a aprendizagem. (Profa. Luz } \\
\text { - EEM Min. Jarbas Passarinho). }\end{array}$ & $\begin{array}{l}\text { Como eram os professores da próp dar } \\
\text { as formações não havia interesse por parte dos } \\
\text { colegas. (Profa. Luz). }\end{array}$ \\
\hline $\begin{array}{l}\text { Uma metodologia reflexiva a respeito da } \\
\text { educação e a prática pedagógica, analisando a } \\
\text { sistematização juntamente com as experiências. } \\
\text { (Prof. Bento da EEM José Cláudio de Araújo). }\end{array}$ & $\begin{array}{l}\text { A coordenação encontrava dificuldade quanto ao } \\
\text { horário de realização do curso. (Prof. Bento). }\end{array}$ \\
\hline $\begin{array}{l}\text { O PACTO tornou possível a troca de ideias e } \\
\text { experiências entre professores e gestores, } \\
\text { possibilitando assim um estudo mais aprofundado } \\
\text { sobre as novas formas de ensino. (Profa. Ana da } \\
\text { EEM José Cláudio de Araújo). }\end{array}$ & $\begin{array}{l}\text { A principal dificuldade foi com relação ao horário } \\
\text { pudessemação participar. (Profa. Ana). }\end{array}$ \\
\hline
\end{tabular}

Fonte: Entrevistas (ARAÚJO, 2019).

A partir das falas, observamos que as informações apontadas pelos entrevistados retratam a percepção enquanto sujeitos que participaram diretamente das atividades propostas nas formações de professores do Pacto, trazendo a avaliação dos aspectos positivos e negativos na implementação das atividades.

Quanto às contribuições das formações, alguns enfatizaram a importância dos conteúdos trabalhados para o fortalecimento da prática docente, possibilitando repensar ações e criar outras, para superar as dificuldades existentes no processo de ensino e aprendizagem. Embora o fato de serem conduzidas pelos pares, sem presença de especialistas da academia, tenha desmotivado alguns professores, como afirmou a professora Luz.

O formato de estudos coletivos, envolvendo áreas diferentes de conhecimento, possibilitou discussões interdisciplinares sobre temáticas essenciais para o Ensino Médio, em consonância com a construção da Base Nacional Curricular Comum- BNCC, permitindo aos professores conhecer as ações pensadas pelo MEC para este nível de ensino.

Por outro lado, a proposta do Pacto de pensar as juventudes como sujeitos da aprendizagem trouxe a oportunidade de desconstruir a visão do estudante como um número ou índice em avaliações, levando os professores a refletirem sobre os contextos socioeconômicos de aprendizagem, o que também foi apontado, por alguns professores, como um dos pontos positivos. Os conteúdos dos cadernos de formação levaram os professores a refletirem sobre os estudantes, seus contextos e a bagagem de conhecimentos que cada um traz para a escola e como a instituição pode colaborar com a aprendizagem e a vida destes. 0 professor Carlos, que atua na escola José Cláudio há mais de seis anos afirmou que adquiriu "[...] uma maior compreensão do universo estudantil, visando entender melhor as dificuldades dos alunos e trabalhar por melhorias".

A EEM Ministro Jarbas Passarinho, em Sobral, atende jovens de bairros considerados de alta vulnerabilidade social, cujos problemas reverberam no ambiente escolar, afetando não só o processo de ensino-aprendizagem, mas também as relações dos alunos com os demais membros da comunidade escolar. A EEM José Claúdio de Araújo atende todos os alunos do município de Mucambo, das zonas rural e urbana. Assim, percebese a multiplicidade das juventudes presentes nas duas escolas. Cada jovem possui interesses 
e capitais culturais diferentes e, como afirma Paulo Freire (2002), "ensinar exige respeito aos saberes dos educandos". Trazer esse entendimento era uma das pretensões do Pacto.

Dentre as dificuldades apresentadas em ambas as escolas, a organização dos horários das formações foi destacada repetidamente nas respostas dos professores, levando a refletir acerca da sobrecarga de trabalho e da priorização dos resultados escolares voltados às avaliações externas. Assim, algumas atividades, como a formação de professores, ficam em segundo plano e os planejamentos são destinados ao estudo de metas, indicadores e descritores das avaliações externas, deixando a natureza dos estudos coletivos de lado, quando deveriam ser estudados e revistos os documentos norteadores do Ensino Médio, textos sobre juventudes, sobre os processos pedagógicos e a própria reflexão das demandas escolares que também incidem na aprendizagem dos estudantes. Ainda pode ser destacado o fato de muitos professores não terem dedicação exclusiva às escolas pesquisadas, fato que dificultou conciliar um horário que atendesse a todos.

Outra dificuldade apontada, em especial pelos professores da EEM Ministro Jarbas Passarinho, diz respeito à falta de compreensão da proposta do Pacto, este foi apresentado apenas como mais um projeto dentre outros a serem implementados na escola, sendo motivados a participar apenas pela bolsa, no valor de $\mathrm{R} \$ 200,00$, destinada a subsidiar o material para estudo.

Diante do exposto, cabe considerar que o Pacto foi implementado e recebido de formas diferentes em cada escola pesquisada. As repostas dos professores da EEM José Cláudio de Araújo, em Mucambo, denotam que este programa apresentou impactos importantes nos processos pedagógicos da escola e que a descontinuidade foi um fator negativo, tendo em vista o trabalho que vinha sendo desenvolvido. Na EEM Ministro Jarbas Passarinho, em Sobral, com base nas informações obtidas, houve uma dificuldade de compreensão das propostas de formação, atreladas à desmotivação em participar e às particularidades da escola, assim, para a maioria dos participantes, o que realmente fez falta foi o incentivo financeiro.

Cabe, portanto, refletir sobre como as políticas públicas são implementadas nas escolas, tendo em vista que as ações pensadas nem sempre conseguem ter os impactos esperados. A análise aqui apresentada revela uma realidade comum no Brasil no que se refere às políticas públicas, em especial, as educacionais. Elas são implementadas sem a análise situacional que permita o entendimento das realidades, projetos e anseios pedagógicos de que cada escola e, por fatores econômicos, ideológicos e políticos, não são priorizadas ou não têm continuidade, deixando de serem avaliadas para, a partir da avaliação, serem repensadas, corrigidas e replicadas. Portanto, o ciclo dessas políticas nunca é cumprido do modo como deveria, o que representa um desperdício de dinheiro público.

\section{Considerações finais}

O PNEM se configurou como marco e política inaugural, especificamente no que diz respeito à formação de professores do Ensino Médio, principalmente por se tratar de uma política com foco de abrangência nacional. Ele buscou fortalecer os planejamentos pedagógicos dos professores, já existentes no cotidiano das escolas, transformando-os em espaços de formação mais democráticos e participativos. Com a troca de experiências entre os professores e a formatação de ações a partir das dificuldades encontradas, assumiu o caráter de formação colaborativa, sem a presença de profissionais especialistas nas temáticas, já que as formações eram mediadas por professores das próprias escolas que assumiam o papel de orientadores de estudos. 
A proposta do PNEM para os professores era de que estes extrapolassem as atividades, trazendo coisas maiores e diversificadas, além do programa já existente, para enriquecer o processo de ensino-aprendizagem na sala de aula. Os objetivos do programa, no entanto, esbarraram na sobrecarga de trabalho dos professores e no excesso de cobrança por resultados nas avaliações externas. Assim, conciliar as horas do planejamento de atividades com as formações que demandam tempo para estudo e discussões mais complexas gerou esgotamento e falta de interesse por parte de muitos professores.

O PNEM contava com financiamento da União para a execução das atividades, e para pagar as bolsas para professores, orientadores, formadores e técnicos responsáveis pela implementação. O corte de recursos, em 2015, afetou o desenvolvimento das etapas e desmotivou o público envolvido.

Analisando as formações oferecidas pelo Pacto em sua curta existência, consideramos que ele tinha potencialidade para atender a muitos anseios e expectativas dos que se envolveram de modo mais direto com ele, uma vez que trabalhou a desconstrução de conceitos enraizados de avaliação, ensino, aprendizagem e possibilitou maior conhecimento das legislações educacionais que influenciam diretamente nos processos pedagógicos do Ensino Médio. Portanto, sua continuidade seria importante, corrigindo os aspectos que foram apontados pelos professores como negativos. Tendo em vista que novos contextos e demandas para o Ensino Médio surgiram, a continuidade das formações permanentes de professores torna-se fundamental para a qualificação dos trabalhos educacionais na última etapa da educação básica.

\section{Referências bibliográficas}

ADAMS, Telmo. 0 desafio das políticas públicas no Brasil. Escola de Formação Fé, Política e Trabalho Diocese de Caxias do Sul: Morro Reuter, outubro de 2006.

ARAÚJO, Maria Cibelle Moreira de. O Pacto Nacional pelo Fortalecimento do Ensino Médio: limeites e possibilidades de Implementação na CREDE 06 - Sobral. Dissertação (Mestrado Profissional e Planejamento e Políticas Públicas), Universidade Estadual Vale do Acaráu UECE, Fortaleza, 2019.

BRASIL. Diretrizes Curriculares Nacionais para o Ensino Médio. Brasília: Ministérios da Educação/Conselho Nacional de Educação/ Câmara de Educação Básica, 2012.

DAYRELL, Juarez. A escola faz as juventudes? Educação \& Sociedade, Campinas, vol. 28, n. 100 - Especial, p. 1105-1128, out. 2007.

FREITAS, Karla Alves; CRUZ, Fátima Maria Leite. Pacto Nacional pelo Fortalecimento do Ensino Médio: formação continuada de professores e trabalho docente em análise. Revista de Administração Educacional, Recife, v. 1, no 1, 2015 jan./jun 2015. p 35-50. Disponível em< https://periodicos.ufpe.br/revistas/ADED/article/viewFile/2338/1880> Acesso em: 23 de julho de 2020.

FREIRE, Paulo. Pedagogia da autonomia: Saberes Necessários à Prática Educativa. 33. ed.. São Paulo: Paz e Terra, 2002.

GOLDENBERG, Mirian. A arte de pesquisar. São Paulo: Record, 1997.

IMBERNÓN, Francisco. Formação docente e profissional: formar-se para a mudança e incerteza. 9. ed. São Paulo: Cortez, 2011. 
LIMA, Luciana Leite; D'ASCENZI, Luciano. Implementação de políticas públicas: perspectivas analíticas. Revista de Sociologia e Política, v. 21, n. 48, p. 101-110, dez. 2013. Disponível em: <http://www.scielo.br/pdf/rsocp/v21n48/a06v21n48.pdf>. Acesso em:15 ago.2018.

MAY, Tim. Entrevista, métodos e processos em Pesquisa Social: questões, métodos e processos. Trad. Carlos Alberto Silveira Neto Soares. 3.Ed. Artmed, 2004.

MORIN, Edgar. Introdução ao pensamento complexo. Lisboa: Instituto Piaget, 1991.

SAVIANI, Demerval. Política educacional brasileira: limites e perspectivas. Revista de Educação PUC-Campinas, Campinas, n. 24, junho 2008. p. 7-16.

SECCHI, Leonardo. Políticas públicas. São Paulo: Cengage Learning, 2010.

SILVA, Ileize. Fundamentos e metodologias do ensino de sociologia na educação básica. In: HANDFAS, Anita; OLIVEIRA, Luiz Fernandes de (Org.). A Sociologia Vai à Escola: história, ensino e docência. Rio de Janeiro: Quartet/FAPERJ, 2009.

MARTINS, Clélia.O que é política educacional.2ed. SãoPaulo: Brasiliense,1994.

MASCARENHAS, Alexandra Garcia. Sociologia no ensino médio: trabalho docente e formação. In: HANDFAS, Anita; OLIVEIRA, Luiz Fernandes de (Org.). A Sociologia Vai à Escola: história, ensino e docência. Rio de Janeiro: Quartet/FAPERJ, 2009.

MAY, Tim. Entrevista, métodos e processos em Pesquisa Social: questões, métodos e processos. Trad. Carlos Alberto Silveira Neto Soares. 3.ed. São Paulo: Artmed, 2004.

OLIVEIRA, Adão Francisco de. Políticas Públicas Educacionais: conceito e contextualização numa perspectiva didática. In: Fronteiras da Educação: desigualdades, tecnologias e políticas. Goiania: EdPUC Goiás, 2010.

TARTUCE, Gisela Lobo B. P.; MORICONI, Gabriela Miranda; DAVIS, Claudia L. F.; NUNES, Marina M. R. Desafios do Ensino Médio no Brasil: Iniciativas das Secretarias de Educação. Cadernos de Pesquisa, v.48, n.168, p.478-504, abr./jun. 2018.

VASCONCELOS, Francisco Herbert Lima. (org). Experiências pedagógicas e formação de professores: pacto pelo fortalecimento do ensino médio no Estado do Ceará. Universidade Federal do Ceará. Recife: Imprima, 2017. 